Bond University

Research Repository

\title{
An interdisciplinary approach in identifying the legitimate regulator of anti-doping in sport: The case of the Australian Football League
}

Gowthorp, Lisa; Greenhow, Annette; O'Brien, Danny

Published in:

Sport Management Review

DOI:

10.1016/j.smr.2015.11.004

Licence:

CC BY-NC-ND

Link to output in Bond University research repository.

Recommended citation(APA):

Gowthorp, L., Greenhow, A., \& O'Brien, D. (2016). An interdisciplinary approach in identifying the legitimate regulator of anti-doping in sport: The case of the Australian Football League. Sport Management Review, 19(1), 48-60. https://doi.org/10.1016/j.smr.2015.11.004

\section{General rights}

Copyright and moral rights for the publications made accessible in the public portal are retained by the authors and/or other copyright owners and it is a condition of accessing publications that users recognise and abide by the legal requirements associated with these rights.

For more information, or if you believe that this document breaches copyright, please contact the Bond University research repository coordinator 


\title{
An interdisciplinary approach in identifying the legitimate regulator of anti- doping in sport: The case of the Australian Football League.
}

\begin{abstract}
:
The regulation of anti-doping practices in Australian sport is overseen by the Australian Sports Anti-Doping Authority (ASADA), which is a statutory authority funded by the Australian Commonwealth Government (ACG). The 2013 ASADA investigation into the Essendon Football Club (EFC) uncovered the alleged use of performance and image enhancing drugs by a number of players and support personnel. However, despite the call for sanctions to be placed on those taking banned substances, ASADA itself became the central focus of enquiry with the EFC questioning the legitimacy of ASADA's authority in their management of the investigation. Using content analysis and Bourdieu's conceptual framework, this paper aims to determine the legitimate regulatory authority of key actors involved in the EFC investigation. The findings suggest actors in the social field, as related to the case of the EFC investigation, possess varying amounts and types of capital, which cumulatively convert to symbolic capital. Dominant actors within the social field retain more symbolic capital than others and are perceived to possess legitimate regulatory authority, which does not translate to actual legal authority. This apparent disconnect between perceived authority on the one hand and actual legal legitimacy on the other has implications for the future management of such cases, both in the Australian Football League and beyond.
\end{abstract}

Keywords: social theory, regulation, legitimacy, anti-doping, AFL 


\section{Introduction}

Doping in sport has been a topic of great interest to scholars across a variety of disciplines from law, management and medicine, to name a few (Fridman \& Buti, 2001; Newton, 2013; Stewart, Adair, \& Smith, 2011). In Australia, the regulation of doping in professional football is a topic that has generated significant scholarly attention in recent times due to issues confronting the Australian Football League (AFL) and the Essendon Football Club (EFC).

In February 2013, a joint presentation, involving Australian Federal Government Ministers and senior executives of a number of sport governing bodies, responded to damaging reports alleging systemic doping practices within a number of elite professional sports in Australia (Gordon, 2013). As such, fundamental questions arose as to the management, regulation and governance of the promotion and enforcement of the Australian anti-doping regime (Australian Crime Commission, 2013) and resulted in a joint media presentation labeled as the "blackest day in Australian sport" (Gordon, 2013). In this paper, we question whether the orchestration of this joint media presentation reinforced the need for collaboration among government and nongovernment actors to jointly tackle anti-doping in the Australian sports system. Specifically, our research question addresses the relationship between organisational capital and legitimacy in the regulation of doping in sport.

This paper adopts an interdisciplinary approach by applying social capital theory in the context of anti-doping regulation in Australian sport, in order to determine levels of organisational capital among key actors. More specifically, the joint investigation into the doping issues in Australian football and the EFC resulted in a variety of actors attempting to assert authority in the regulation of anti-doping in Australia. As a result, there was confusion as to which actor was the legitimate regulator, and whether or not 
that actor had the necessary authority and regulatory power to control doping regulation in this country. For the purpose of this paper, a regulator can include government and non-government actors in charge of establishing rules and regulations to be followed by others within that regulatory domain.

The notion of capital and regulatory authority within sport organisations is not new to sport management as researchers have investigated the role of capital to influence change both within organisations and the organisational fields within which they operate (Cousens \& Slack, 2005; O'Brien \& Slack, 2003; Stewart et al., 2011). However, the link between capital, regulation and the legitimate authority of an organisation has remained surprisingly under-investigated within sport management research. Previous research has identified dominant stakeholders within an organisational field in relation to the levels of capital they possess (O'Brien \& Slack, 2003, 2004; Stewart et al., 2011). However, no studies have addressed the connection between the legal regulatory authority of actors and the perceived levels of organisational capital possessed by these actors.

In the context of this paper, we argue that legal regulatory authority (or legitimate authority) can derive from contractual or legislative sources and is thought to underpin the legitimacy of the authority that organisations seek to exert within their organisational field. The concept of regulation is applied in order to determine what organisation has the power to legitimately regulate anti-doping in Australian sport. The paper also investigates those organisations that are perceived to have legitimate authority within a given social field, which is determined by the capital they possess as opposed to the legislative authority awarded them. Thus, the inclusion of legal authority in this discussion surrounding regulation and legitimacy seeks to contribute to the identified gap in the literature. 
Through the application of Bourdieu's social theory and using content analysis, we seek to determine the nature of individual capital possessed by the actors involved in the EFC doping allegations and the subsequent joint investigation by the AFL and ASADA. An examination of legal and regulatory instruments provided a means to determine the legitimate authority afforded to those organisations being examined. We posed the question, "what is the relationship between organisational capital and legitimacy in the regulation of doping in sport?' To address this question, our goals were to: (1) identify the key actors involved in the EFC doping allegation; (2) identify the type and level of capital each actor possessed; (3) establish the perceived authority associated with the different types and levels of capital; and last, (4) determine the legitimate authority of each actor within the doping in sport social field, based upon the extent of their legal authority. In other words, government actors as state regulators act within the parameters of their legislative powers given under the relevant legislative instrument. Non-government actors do not have the legislative authority but may possess other forms of legal and regulatory authority that is often of equal significance.

\section{Theoretical Framework}

To assist in understanding the regulation and governance of anti-doping in Australia and specifically, in the analysis of the case of the EFC, Pierre Bourdieu's social theory concepts were applied. Bourdieu's social theory has been adopted by a number of sport management researchers (Augestad, Bergsgard, \& Hansen, 2006; O'Brien \& Slack, 2003). Indeed, Kitchin and Howe (2013) believe the use of Bourdieu's work can lead sport management researchers to a greater understanding of the, "interplay between micro and macro pressures within the organisational field" (p. 132). 
Bourdieu's contribution to sociology revolves around three key concepts: social field, capital and habitus (Swartz, 1997). Bourdieu did not examine organisations per se; instead, he sought to understand the setting (social field) in which actors (agents and stakeholders) operated. According to Everett (2002), Bourdieu examined the struggle of actors attempting to achieve power, prestige and influence over those within the social field. As such, Bourdieu sees organisations in relational contexts that can only act within a given social field.

\subsection{Social Field}

The concept of the 'social field' is central to understanding Bourdieu's social capital theory. Bourdieu (1990) described the social field as, "networks of social relations, structured systems of social positions within which struggles or maneuvers take place over resources, stakes and access" (Bourdieu, 1990, p. 53). In other words, this 'field of action' sees particular capital valued or devalued by the actors occupying the social field, through the intersections between relations of power that determine the dominant actors within the field.

The social field contains dominant and dominated actors that aim to establish supremacy over other actors within the field through the use of power, influence and domination (Everett, 2002). The dominant actors possess various forms of capital that contribute to their perceived power and status within the social field. Conflict and competition occurs among actors as they attempt to, "accumulate, conserve or convert different types of capital" into influence and authority (Ihlen, 2007, p. 270). Within a social field, authority, influence and prestige vary among actors, as each attempts to accumulate capital, which is seen as a source of power (Swartz, 1997).

According to Pellandini-Simanyi (2014), "fields are organised around specific stakes that all participants of the given field pursue. These stakes are always a form of 
symbolic power, which is granted on different grounds in each field" (p. 656). In the case of the EFC, these stakes could represent reputation, drug-free sport and authority. Bourdieu (1990) suggested that actors engage in a constant struggle to maintain or improve their position within the social field by creating reliable access to these stakes. Indeed, Bourdieu (1996) believed each field participant attempts to, "impose boundaries within the field that are most favourable to its interests" (p. 223).

In the social field examined in this research, the involved actors include the AFL, ASADA, ACG, AFL clubs (including the EFC), fans, sponsors, sport broadcasters and the wider mass media. In Australia, the AFL dominates the sporting landscape, as the preeminent spectator sport in the country (Australian Government, 2015). Furthermore, Australian Rules football participation in club-level leagues continues to dominate other participation sports around the nation (Australian Bureau of Statistics, 2015). As a result, the AFL has developed significant authority, reputation and popularity within the Australian sport culture, and has done so in a manner consistent with values related to drug-free participation. In this sense, the AFL is a dominant force that has accumulated significant levels of capital within the social field examined in this research.

\subsection{Capital}

Bourdieu (1985) identified several types of capital including; economic, symbolic, social and cultural. Interestingly, Bourdieu believed symbolic capital relates to the symbolic power of the actor, where authority, knowledge and reputation are used to influence behaviour within the social field. According to Sideri (2004), power is essential in "any analysis seeking to explain action" (p. 66). As Bourdieu (1985) explained, "in the struggle to impose the legitimate view of the social world, agents [actors] yield power proportionate to their symbolic capital” (p. 731). Symbolic capital 
in its simplest form is often seen as a collection of economic, social and cultural capital; however, it is also a function of an actor's status and reputation (Stewart et al., 2011). Bourdieu (1984) implies symbolic capital accrues as the residual effect of actors claiming status, building reputation and securing social gravitas. As such, symbolic capital can also be defined as, "a reputation for competence and an image of respectability and honorability" (Bourdieu, 1984, p.291). Thus, an actor's symbolic capital is the perceived power to make things happen as a result of the legitimate position occupied in the field (Bourdieu, 1985). This notion of 'legitimate position' refers to the collective symbolic capital an actor possesses in the social field that contributes to the perceived power and influence they wield within that social field.

It is worth noting that Bourdieu calls "legitimate power symbolic power, by which he means the kind of power that is reinforced by authority (as opposed to, say, sheer force)" (p. 655). However, power and authority as defined by Bourdieu are contained to the social field in which an actor occupies. Thus, Bourdieu's use of the concept 'legitimate power' is different from the concept of 'legitimate authority', a term we have used throughout this paper to reflect the legislative power an organisation may possess, that is not necessarily confined to a social field. These concepts are discussed further in the following section.

Consequently, symbolic capital is therefore misrecognised in the social field. In other words, "symbolic capital operates through misrecognition as authority and the power to shape main-stream understandings and is often premised on taken for granted perceptions of the social world" (Sideri, 2004, p. 67). The notion of 'misrecognition' pertains to the manner by which power is perceived by other individuals within the social field. Where symbolic capital is grounded on actors' misrecognition of authority and power, a vicious cycle can evolve within a social field where the production of 
symbolic capital serves to reproduce the field's social order (Sideri, 2004). Thus, those actors with significant symbolic capital within a given social field are perceived by other actors as legitimate regulators of that social space, even without the actual legal authority to regulate behaviour. As a result, their symbolic power is a source of influence over the behaviours, values and norms of the social field (Ihlen, 2007).

Social capital, on the other hand, refers to an actor's network of acquaintances, which contributes to the power and resources the actor acquires within the social field (Emirbayer \& Johnson, 2008). Social capital adds value to the perceived symbolic capital of an actor within the social field. Thus, it is suggested that all forms of capital (economic, social, cultural) are interconnected and as a result are converted to symbolic capital, making it the definitive source of power (Everett, 2002). As a result, those actors with the most power attempt to alter relational dynamics in the social field through shifts in logics, norms and values (Washington \& Patterson, 2011).

\subsection{Habitus}

The term "habitus" refers to a set of acquired values, dispositions, perceptions and appreciations which give meaning to our practices (Bourdieu, 1990). Habitus, therefore, is a structure or system that provides strategies for actors within the field by which to relate to the social world (Ihlen, 2007). It is seen as a "structured structure" by the effects of the actions and interactions with others in the social space, and also as a "structuring structure" in that it advocates and constrains future actions (Bourdieu, 1990).

According to Bourdieu and Wacquant (1992), a habitus is based on all the situations through which dispositions are created and stems from individual experiences throughout a lifetime. Therefore, each member of the social field brings to it a habitus formed from past experiences and conditions. Building on this work, Emirbayer and 
Johnson (2008) suggested that by examining habitus and the micro-processes of individual behaviour within a social field, a deeper understanding of the development of organisational and relational structures occurs.

The connection between habitus and the social field is termed doxa and is defined by Bourdieu (1990) as, "the interrelationship of immediate adherence that is established in practice between a habitus and the field to which it is attuned" (p. 68). In other words, the doxa may control the barriers to actors entering the social field. A social field can be described as the 'space of play' and the interaction between habitus and the field thought of as 'a feel for the game' (Bourdieu, 1990).

The use of Bourdieu's social theory for this research aims to determine the type and level of capital possessed by both ASADA and the AFL in relation to their respective roles in the investigation into the EFC doping allegations. The use of Bourdieu's concepts are not new to sport management research, as investigation into organisational behaviour and organisational change within sport organisations is a popular research paradigm (Ferkins, Shilbury, \& McDonald, 2009; Houlihan, 2013; O'Brien \& Slack, 2003, 2004; Shilbury \& Ferkins, 2011; Slack \& Hinings, 1992). O'Brien and Slack $(2003 ; 2004)$ engaged Bourdieu's work in their investigation of the mechanisms of change in the professionalisation of English rugby union. Their findings highlighted that the social field reflects the habitus of dominant agents; thus, change occurs when new actors in possession of legitimate forms of capital enter the field and alter prevailing logics in accord with their own habitus. Similarly, research from Cousens and Slack (2005) and Washington and Ventresca (2008), examined field-level conflict and organisational change as a result of new entrants into the field. 
More specific to sport doping, a study by Stewart et al., (2011) examined illicitdrug regulation policy using Bourdieu's three primary concepts as outlined above. The use of Bourdieu's model of social behavior determined that:

The accumulation of capital can shore up the power base of a class or collective habitus and highlights the ways in which this power can be used to impose values and dispositions on other agents and organisations, and consequently dominate a social field (p. 241).

The recent case of EFC and the investigation into doping allegations leveled against it calls into question the conclusions made by Stewart et al., (2011). The protracted nature of the case is essentially the product of a contestation over the legitimacy of the symbolic capital and related authority possessed by the field's dominant actors. Therefore, this research extends the work of Stewart et al., (2011) by first, determining the dominant actors within the regulation of doping in Australian sport and then identifying the legitimate authority those dominant actors possess within this social field. Furthermore, examining the habitus within the organisational field will highlight the dominant actor/s responsible for the values and behaviours occurring within this social space. According to Kitchin and Howe (2013), understanding social habitus in sport management is under-researched, and they call for further research that offers a relational analysis of field, capital and habitus to determine aspects of power within the management of sport. In addition, they suggest future research could examine how organisations gain capital and what field strategies are implemented by the dominant organisations in the social field in order to maintain levels of power and control. This paper incorporates these suggestions to determine the legitimate authority of actors involved in the investigation of the EFC, and the strategies they employ to maintain their legitimate authority. A brief background to the EFC doping allegations 
and subsequent investigation is required to provide an understanding of the social field examined in this paper.

\section{Background to the Study}

Drug-free status is the central plank that underpins the international conventions against doping in sport embodied in the World Anti-Doping Agency (WADA) Code the universal statement of anti-doping policy that is practiced globally (WADA, 2014). It is a well-researched area across many disciplines with the unified purpose of understanding the concept of pure performance in sport (Corlett, 2013; Dickinson \& Quirk, 2010; Eichner, 2008 \& Houlihan, 2014).

The Australian sports system is a top-down hierarchy overseen by the federal government. The Australian Sports Commission (ASC), a federal agency, is the government body responsible for overseeing the governance, management and funding of National Sporting Organisations (NSOs) which are responsible for domestic competition and achieving success at international sporting competition (Australian Sports Commission, 2009b). ASADA, also a federal agency funded by the ACG, works in partnership with the ASC to ensure drug-free sport in Australia.

\subsection{Anti-Doping Regulation in Australia}

Australia was a signatory to the 2004 Copenhagen Declaration and the 2005 UNESCO International Convention against Doping in Sport, agreeing to bring the Australian anti-doping regime into compliance with the WADA Code and the international movement to preserve the integrity of sport from the threats posed by doping (Thorpe, Buti, Davies, Fridman, \& Jonson, 2013). After amending the existing legislative powers and the limited role of the former regulator, the Australian Sports Drug Agency (ASDA), the ACG introduced the Australian Sports Anti-Doping Authority Act in 2006 and replaced ASDA with a new regulator, ASADA, with a vastly 
expanded role conferring substantial additional investigative powers. ASADA operates as a statutory regulator, acting independent of any influence from government or sport organisations and is unfettered in the execution of its functions (Andrews, 2005; Lundy, 2006).

The National Anti-Doping Scheme (NAD Scheme) was enacted under the ASADA Act and establishes the regulatory framework that ASADA must follow in implementing the objectives of the ASADA Act, which in turn, embody the WADA Code (ASADA, 2006a). As such, ASADA is vested with the legislative authority to regulate the WADA code, investigate suspected doping rule violations and enforce the Anti-Doping Rule Violations under the WADA Code within Australian sport. ASADA therefore, has the legislative power to issue show cause notices for suspected AntiDoping Rule Violations and to refer matters to the Anti-Doping Rule Violation Panel for determination (ASADA, 2006a, 2006b).

Amendments made to the ASADA Act in 2013 significantly increased the investigative powers of ASADA by enabling the CEO to issue disclosure notices against athletes and their support personnel suspected of participating in doping. These notices enhanced the evidence-gathering function of ASADA and prescribed significant penalties for non-compliance (ASADA, 2006a). As indicated above, despite its status as a government agent, ASADA should act independent of political or other interference in executing its functions as the regulator of the anti-doping regime in Australian sport.

\subsection{The Australian Crime Commission Report}

The Australian anti-doping regime was predicated on the platform of athlete health and welfare and public interest policies in preserving the integrity and "spirit" of sport (Thorpe et al., 2013). An investigation by the Australian Crime Commission (ACC) in 2011 uncovered evidence of systemic doping practices and widespread use of 
Performance and Image Enhancing Drugs (PIEDs) within two of the professional football codes played at the elite level in Australia. These allegations threatened the integrity of sport by drawing links between doping in sport and organised crime (Australian Crime Commission, 2013). Up until the release of the ACC Report in 2013, doping issues in team sports in Australia had been confined to a few cases of individual players within teams and had never arisen in the context of systemic doping practices involving an entire team (Moston, Engelberg \& Skinner, 2015) .

\subsection{The Australian Football League}

One of the football codes implicated in the ACC Report was Australian rules football, Australia's most popular spectator sport, with annual revenue in 2013 of \$446 million and total annual attendance figures exceeding 6.3 million spectators with an average game attendance of 32,000 (AFL, 2013a). Australian rules football, formerly known as Victorian rules football, originated in Victoria in 1877 and is Australia's oldest non-indigenous sport (Linnell, 1995). The Australian Football League (AFL), as a company limited by guarantee, is the national governing body of the code. The AFL is responsible for the organisation and regulation of the national competition involving 18 licensed teams with 810 active players (Harcourt, Marclay, \& Clothier, 2014). In terms of revenue and value of its broadcasting and licensing rights, the AFL dominates the Australian sporting landscape and is financially independent of government, yet benefits from partnerships and pathway programs with the ACG (AFL, 2013a).

The allegations in the ACC Report were made against a number of professional clubs, players and support personnel suspected of engaging in systemic doping practices in the 2012 season (Australian Crime Commission, 2013). One of the 18 clubs participating in the AFL is the Essendon Football Club (EFC). Upon being 
identified as one of the clubs under investigation, the EFC self-reported its involvement in the alleged doping practices to ASADA (Evans, 2013).

\subsection{The ASADA/AFL Investigation}

Following the actions by the EFC in self-reporting, the Chief Executive Officer (CEO) of ASADA and the AFL entered into an agreement and commenced a joint-investigation into the legality of the supplements program at EFC (Harcourt et al., 2014). Harcourt et al., (2014) concluded that one of the reasons for this collaboration was the extensive financial and non-financial resources available to the AFL. These resources included the forensic capabilities of the AFL investigators and its internal integrity unit, together with the AFL's considerable financial resources. Further, the tripartite contractual nexus existing between the AFL, the clubs and the players, enabled the AFL to assert legal authority over registered players to compel them to co-operate in the execution of ASADA's functions (Andruska, 2014). The investigation was to last for seven months, involving 130 interviews and collaboration between AFL and ASADA integrity investigators and technical experts. The cost to the AFL of the joint investigation was estimated to be $\$ 1.3$ million (Harcourt et al., 2014). The information gathered during this investigation led to the issuing of show cause notices against 34 EFC players under the NAD Scheme. In addition, the AFL imposed sanctions upon the EFC and a number of support personnel and officials (AFL, 2013b). Immediately following the issue of show cause notices against the EFC players, Federal Court proceedings were filed by the EFC against the CEO of ASADA alleging that the joint investigation was beyond the scope of ASADA's authority (Australian Federal Government, 2014a). The EFC claimed that the joint investigation was invalid and sought an order setting aside the notices issued to the 34 EFC players (Australian Federal Government, 2014a). The EFC Court Proceedings were heard before Justice 
John Middleton of the Federal Court of Australia in August 2014 and a decision was delivered on 19 September 2014. The Court determined that ASADA was not acting outside its powers and complied with the rule of law in establishing and conducting the EFC investigation (Australian Federal Government, 2014b). Of significance in the case was the evidence that suggested confusion as to the legitimate authority of ASADA and the AFL in the management of the anti-doping regime. Further, the revelations in the evidence suggested the AFL and ACG applied pressure to ASADA, raising questions as to the legitimacy of the 'independent' status of ASADA. While the Federal Court's decision is significant to establish the legal legitimacy of ASADA based on a narrow construction of its regulatory power, the commencement of the proceedings was precipitated on the basis of confusion as to regulatory actors, their responsibilities and external pressures brought to bear on getting a result. Hence, this paper assays those actors involved in the EFC case and evaluates the legitimacy of their authority within the context of doping in Australian sport by examining the nexus between regulation, capital and legitimacy.

\section{Regulation and Legitimacy}

For the purpose of this paper, and to contextualise regulation as being more than government action based on legislative authority, Black's (2002) approach to regulation is applied and taken to mean any intentional action by an actor designed to alter or influence the behaviour of others. The 'others' in the context of regulation are classified as 'regulates' or targets whose behaviours are intended to be altered or influenced by the regulatory interventions. Regulation is pervasive and in some cases operates quietly to shape and preserve social order within a particular context (Freiberg, 2010). In other cases, regulation is obvious and easily identifiable. In all cases, regulation is much 
broader than just reference to government intervention and extends to non-government actors who are in positions to alter or influence the behaviour of others.

\subsection{Regulation}

Regulatory authority in the present context of the Australian anti-doping regime is taken to be the legal authority that establishes the legitimacy of the actor. The term 'legitimacy' in the context of this paper suggests the lawful authority of an actor to regulate in a way that ultimately influences the behaviour of others. The role of government as a dominant actor in the social field leaves the substantive elements to others to implement, interpret and enforce rules relevant to its environment. This 'hands off' approach to regulation does not mean that government disappears altogether. Westerman (2010) suggests that the biggest deterrent to regulatory reconfiguration is the threat of 'substantive self-regulation' where government stands ready to intervene and impose onerous and less benevolent forms of regulation should self-regulation fail to achieve its regulatory objectives. According to Parker (2002), achieving a healthy balance between external influences of government, stakeholders and communities with internal management — described as 'open' or 'permeable' self-regulation—leads to more efficient, effective and legitimate regulation.

In the present case, the ACG established ASADA as the state agency whose authority and legitimacy is underpinned by legal regulation, this being the ASADA Act and NAD Scheme. Consistent with administrative law principles, the function of ASADA as a government agency should operate within the legal framework of the ASADA Act and operate independent of any political influence or other pressure from external participants (ASADA, 2006a). At the time when the ASADA Bill was introduced in the Australian Parliament in 2005, the independent and transparent nature 
of ASADA's functions received unequivocal bipartisan support (Andrews, 2005; Lundy, 2006).

The AFL and EFC are non-government actors. In the case of the AFL, its legitimacy is referable to its position as the ultimate controller and regulator of the national competition of Australian rules football. By having the power to grant clubs licenses to participate in the national competition, the AFL's legitimacy is established through contractual arrangements which bestow the power to establish and enforce its policies and codes of conduct within its sport (AFL, 2014). For those reasons, the AFL has been classified as a dominant regulator and custodian of its sport (Greenhow \& East, 2014). The EFC is a club licensed by the AFL to participate in the AFL national competition, and this contractual arrangement requires the EFC to comply with AFL regulations, player rules and the Anti-Doping Code (AFL, 2014). In return, the EFC receives annual distributions from the AFL. In 2013, the AFL distributed \$209.2million to clubs within the national competition, with the EFC receiving $\$ 8.4$ million as part of the AFL annual distribution (AFL, 2013a; Essendon, 2013). The EFC itself is the employer of players and other persons connected with the EFC's participation in the AFL competition.

\subsection{Legitimacy in regulation}

Regulation attains its legitimacy by being instituted upon a clearly defined and evidence-based foundation. One reason to regulate is when public confidence is threatened and citizens look to government to act on their behalf to produce certain regulatory outcomes (Parker, 2002). Such is the case with the establishment of ASADA and the investment in anti-doping regulation in Australia. However, various definitions of 'legitimacy' exist and such definitions are often associated with a specific context. For example, Suchman (1995) offers a working definition of legitimacy in the context 
of organisations, suggesting that legitimacy can be viewed as, "a generalised perception, or assumption that the actions of an entity are desirable, proper, or appropriate within some socially constructed system of norms, values, beliefs and definitions” (p. 574).

Similarly, Stewart and Smith (2010) suggested that, "legitimacy is reinforced by institutions and people with authority and resources to direct the behaviour and actions of others" (p. 189). In their research, Stewart and Smith (2010) investigated the role of ideology in shaping drug use regulation in Australian sport. They concluded that, "sport in Australia is value-laden where beliefs and assumptions about social significance drive its structure and operation" (p. 194). Hence, ideology is a means of legitimising existing hierarchies, securing control and maintaining power.

Stewart et al., (2011) examined the drivers of illicit drug use regulation in Australian sport and concluded that regulatory arrangements around that issue were based mainly on intuitive notions on player morality and the social values of sport. This questioned the legitimacy of the regulatory arrangements and suggested that, rather than being evidence-based, they were more the product of the 'ideological will' of dominant stakeholders. Similarly, research conducted by McDermott, Henne and Connor (2013) questioned the legitimacy of anti-doping regulation due to the perception that the regulatory framework was based upon it being a 'good thing to do'; thus, being driven by values rather than legal foundations.

This paper analyses the EFC doping case to determine the dominant and legitimate regulators with actual authority to influence behaviour within the anti-doping social field of Australian sport. The research methods employed will now be presented.

\section{Method}

Case study research is conducted in a real-life context that allows the investigation of a particular situation, event, program or phenomenon (Edwards \& 
Skinner, 2009) and is designed to examine significant factors that occur within a set context, rather than examining these factors in isolation (Yin, 2003). The investigation into the EFC following the ACC Report allegations is the case examined in this paper. In order to provide context and understanding of the case in question, content analysis was undertaken.

\subsection{Data Collection}

For this research, government, legislative, court, and organisational documents associated with the joint ASADA/AFL investigation into the EFC were collected. The nature of these documents was publically accessible and freely available by searching the relevant websites. Further, public interest in the EFC investigation resulted in the Federal Court of Australia making the court proceedings and pleadings available freely on its website. In addition, we reviewed the legislative process that underpins the legal authority of the anti-doping structure in Australia. Table 1 outlines the materials that were collected and examined for this research. The authors acknowledge that certain documents, conversations and agreements regarding the EFC investigation and the collaboration between the AFL and the EFC may not have been made public, thus relying only on the information admitted to the public is a limitation of this research.

\section{Insert Table 1 here}

\subsection{Data Analysis}

Content analysis can be done on any form of communication, including textbooks, journals, emails, websites and reports (Miles \& Huberman, 1994). It is used to make replicable and valid assumptions from data within a set context, to provide 
insight, knowledge and the opportunity to guide further research action (Krippendorff, 2004). In undertaking content analysis of the sources referred to above, data were sorted using a deductive approach that incorporated the use of an a priori code template (Crabtree \& Miller, 1992). According to Neuman (2003), researchers often begin coding with a list of codes derived from theories and concepts within a focal area of inquiry.

In this case, three codes were used to classify the data and to assist in addressing the research questions. The codes emerged from an initial review of the literature and were aligned to Bourdieu's conceptual framework, where the researchers attempted to identify the key actors in the social field, and the level of capital, legitimacy and authority they possessed. In-depth discussions among the researchers occurred to finalise the a priori codes and to ensure they would assist in addressing the research questions and capture all relevant information effectively. Thus, the a priori codes used were: (1) Actors and Organisational Capital; (2) Legitimacy; and, (3) Regulatory Authority.

Once the a priori codes were established, each researcher independently examined the documents in order to classify data within each code, with additional information that did not apply to the codes allocated to a separate code 'Other' to be examined at a later date. There were minimal data coded to the 'Other' category due to the broad nature of the a priori codes, and no disagreement amongst coders as data could be placed in one or more of the a priori codes.

As an example, the type of text coded to the Legitimacy code included: "Under the ASADA Act and the NAD scheme established under the Act, ASADA has the legislative authority to investigate possible violations of the anti-doping rules..." (AFL, 2013c, p. 8). The text indicates ASADA's legitimate authority over the AFL in relation to anti-doping violations, hence identifying its legitimacy within the social field being 
examined. Thus, data within this specific a priori code related to any action taken by the actors in regards to the legitimate regulation of anti-doping policies.

While classifying data into each a priori code, each researcher identified subcodes within each a priori code to further assist in the classification of the data. From there, the research team collectively examined the sub-codes looking for overlap and a way to condense sub-codes through commonalities. The process of condensing the identified sub-codes involved the delineation of codes into major themes that would account for all sub-codes. For example, the condensed sub-codes determined by the research team for the Legitimacy a priori code included: legislative power; perceived legitimacy versus actual legitimacy; and authority. As a result, a theme within the Legitimacy a priori code that reflected the identified sub-codes was; perceived and legitimate authority of actors within the social field. In the next section, the themes from all a priori codes are presented narratively through direct quotations in order to capture the meaning and complexity of phenomena being investigated.

\section{Results and Discussion}

\subsection{Perceived and Legitimate Authority of Actors within the Social Field}

Applying Bourdieu's conceptual framework, Ihlen (2007) acknowledged that actors within a given social field hold varying types and levels of capital which can often be perceived as authority to influence and alter behaviour. As noted earlier, Bourdieu's (1985) contention that symbolic capital legitimises an organisation's position in the social field and bestows prestige and reputation is particularly relevant to this research.

In this case, perceptions of legitimacy develop within the social field; thus, actors are thought to have a skewed perception of legitimacy due to the habitus that provides an unconscious sense of the social world (Pellandini-Simanyi, 2014). As a 
result, actors in the social field believe they, "subjectively experience their actions as value driven, [however], objectively these normative stances can be shown to be conducive to acquiring power" (p. 657). In other words, behaviours by less dominant actors are often guided by the need to acquire symbolic capital and power in the social field and less by compliance to the legitimate authority (regulator), as dictated by legislation. In this case, ASADA is the legitimate regulator; however, the behaviours of the AFL and the EFC suggest an attempt to accrue symbolic capital within the social field.

A significant finding in this research highlights the limited power a legitimate authority or regulator may have within a given social field. As discussed in Section 3.1, ASADA has legislative power in all anti-doping matters in Australian sport. By law, ASADA is recognised as the legitimate regulator and is tasked with the power and authority to investigate alleged doping in Australian sport. However, relying on Bourdieu's social capital theory, legitimate authority does not necessarily transform into legitimate power or symbolic capital (Bourdieu, 1990). Therefore, within a social field, perceptions of legitimacy have more bearing on behaviour than does legitimate authority. For example, ASADA was ineffective in its attempt to investigate the EFC doping incident single-handedly. As a result of collaboration with the AFL, ASADA was successful in gaining access to players and the undertaking of 130 interviews. Bourdieu (1990) suggested that each actor within the social field possesses varying levels of capital. Through this capital, perceived legitimacy arises within the focal social field, and in this case, the AFL is seen to retain significant levels and types of capital. Table 2 outlines the capital possessed by those actors occupying the social field in the current case. 


\subsubsection{Perceived authority}

As presented in Table 2, the AFL has comparatively high levels of economic, social and cultural capital, which cumulatively, converts into significant symbolic capital. As a result, the AFL is perceived to have significant power, prestige and authority within this social space and can be considered the dominant actor in the social field (Bourdieu, 1985). Consequently, the AFL's access to power and authority makes it well positioned to instill certain dispositions within the social field and influence the doxa. Bourdieu (1985) implied the possession of symbolic capital by dominant actors provides the means to reproduce the social order within the field. In other words, the AFL has created the norms, behaviours and values within the social field that are accepted and adopted by the field's actors. Since the AFL is deemed to be a dominant actor due to the capital it has acquired, the habitus of the social field is not challenged. This dominance perhaps explains ASADA's admission that it, "was not ready for an investigation of this magnitude" (McDevitt, 2014), and relied upon the authority and legitimacy of the AFL to "assist" with the investigation.

Furthermore, outlining why ASADA pursued a joint investigation with the AFL in her affidavit in Essendon Football Clubv Chief Executive Officer of the Australian Sports Anti-Doping Authority.

Aurora Andruska, former CEO of ASADA, made the following statement:

During the teleconference Mr Clothier said, 'we have the powers'. I understood him to mean that the AFL would use its powers under its contracts with players/officials and its Players Rules, which incorporated its Anti-doping Code, 
to compel players/officials to attend interviews and to answer questions from ASADA investigators truthfully. I said the words, 'we can use the AFL's powers until we get our own powers' (Andruska, 2014, paragrah 11).

Thus, ASADA aimed to accrue power by association with the AFL in order to gain access and cooperation from other actors within the social field. As suggested by Bourdieu (1985), actors gain legitimacy and power within the social field proportionate to their symbolic capital. Therefore, ASADA sought to gain social and symbolic capital through their collaboration with the AFL. The issue at hand is the perceived legitimate power of the AFL within the social field and as Ihlen (2007) contends, less dominant actors' perceptions of the social order of their field can result from misrecognition of the authority and power wielded by dominant actors. As a result, this may have significant implications for the determination of the field's habitus. In this case, ASADA, despite legal authority to conduct investigations, was not perceived by actors in the social field to be dominant. This perceived lack of authority prompted ASADA's decision to combine forces with the AFL in an effort to access the AFL's social and symbolic capital so that it could undertake the investigation.

The AFL has accrued significant symbolic capital since its establishment. The AFL is the richest Australian sporting organisation and has a cultural significance unparalleled to any other football code in Australia. In its latest Annual Report (AFL, 2013a), the AFL's annual revenue was $\$ 446$ million, with average attendance at weekly matches of 32,414 in 2014 . It attracts the highest value for the licensing of its broadcasting rights, with the next round of negotiations valuing these rights close to AUD \$1.6 billion in 2016. In terms of cultural significance, the AFL's unmatched attendance figures and broadcast rights valuation, indicates its importance to the Australian populace, and further solidifies its dominance in the social field. Clearly, the 
AFL's popularity in this country has implications for the comparative health of its economic capital; the AFL is clearly well resourced and has the capacity to promote its objectives and offer its resources to assist in the promotion of the anti-doping regime.

Following analysis of Essendon $v A S A D A$, we contend that perceived authority as a result of symbolic capital is sometimes independent of any legal (legislative) authority an actor may possess. In other words, the authority dominant actors such as the AFL yield within a social field may not be legally authorised. Meanwhile, the social field's subordinate actors are limited in their ability to change the behaviours of the dominant actors, or greatly influence the habitus of the social field. As noted by O'Brien and Slack (2003), change may only occur when new actors that possess highly prized capital enter the social field and alter the habitus. However, the AFL's dominance within its social field extends to heavy influence over those within or planning to enter the field, which thwarts the threat of influential new entrants challenging the status quo.

\subsubsection{Legitimate authority}

A key focus of this research was to determine the legitimate authority actors possess in order to regulate the anti-doping regime. As noted above, the AFL is seen as a dominant actor in the social field and as such, is perceived to have power, authority and influence over other actors. However, Bourdieu's theory does not imply legitimate regulatory authority. Access to significant levels of capital only offer a perception of regulatory authority or legitimacy. So we question, what actual legal authority do the actors in the social field possess? Furthermore, is this legal authority influential in modifying behaviours relating to doping in sport?

In terms of the involvement of the AFL in the investigation of the EFC, the question as to whether the AFL unduly influenced ASADA in order to position itself within the investigation, or whether ASADA simply required assistance from the AFL 
in terms of economic and symbolic capital, is a cogent one. The findings suggest legitimate authority or legal accountability as represented through legislation and legal documents is somewhat unclear. ASADA, at least prior to the 2013 amendments, was necessarily dependent upon the AFL in carrying out the EFC investigation. For example, in the affidavit of then ASADA CEO, Aurora Andruska: "At this time, ASADA had no compulsory powers of its own and was generally reliant on the cooperation of sports bodies in order to be an effective regulator" (Andruska, 2014, paragraph 46.2).

This statement demonstrates the disconnect between perceived authority on the one hand, and legal legitimacy on the other. It is a result of this disconnect that the EFC filed proceedings in the Federal Court suggesting the collaboration between ASADA and the AFL was unlawful, thus rendering the show cause notices handed to players invalid. Therefore, the lawful relationship between the actors in the social field being investigated requires further consideration.

\subsection{Actors and their relationships within the social field}

The actors identified as occupying positions in the regulation of doping in sport in Australia, and specifically the case examined in this paper, includes the ACG, ASADA, the AFL and the EFC. Of course, other actors have influence in this social field, such as players, fans, media, and sponsors; however, the focus of this paper is on the dominant actors with authority to alter or influence behaviour as it relates to doping in sport. The dominant organisations in this social field are ASADA and the AFL.

\subsubsection{The Relationship between ASADA and the AFL}

Under the ASADA Act, the AFL is classified as a sport administration body (ASADA, 2006a). It must at all times have in place, maintain and enforce anti-doping policies and practices that comply with the WADA Code and the NAD Scheme. 
Specifically, the AFL is required to cooperate with any investigations, and ensure its staff cooperates with the CEO of ASADA. Further, the AFL is required to provide the CEO of ASADA with appropriate details or reports relating to investigations, hearings, appeals and sanctions (ASADA, 2006b).

ASADA has the legislative authority to enforce the anti-doping regime. Under the ASADA Act and the NAD scheme, the CEO of ASADA is authorised to investigate possible anti-doping violations committed by athletes and support persons. This legislative framework is the source of ASADA's legal authority (ASADA 2006a; ASADA 2006b). In order to perform its functions, ASADA necessarily has to interact with the sport governing body, and in the case of the AFL and the EFC, this played a pivotal role in the gathering of evidence to support the legality of the show cause notices to the EFC players and personnel. As indicated above, the investigation cost the AFL \$1.3million (Harcourt et al, 2014). These costs were borne by the AFL and not directly by ASADA, saving recourse to taxpayer funds for that component of the investigation. The costs associated with the AFL's Anti-Doping Tribunal determination of the issues facing the EFC are yet to be quantified.

\subsubsection{The Relationship between ASADA and the EFC}

As the regulator with legislative authority to implement doping controls, ASADA has the direct right of access to clubs and players to investigate suspected doping violations. In the case of the EFC, ASADA had direct access to the EFC players in order to perform its functions in the prosecution of the suspected doping violations. Amendments to the ASADA Act in August 2013 enhanced ASADA's investigative powers by enabling the CEO to issue disclosure notices directly to suspected persons, who faced a significant penalty for non-compliance. Prior to these amendments, ASADA did not possess sufficient symbolic capital and depended upon the AFL's 
capital to enable it to perform its functions in the EFC investigation. The acquired social capital from its "partnership" with the AFL provided ASADA the opportunity to increase its symbolic power within the social field.

\subsubsection{The Relationship between the AFL and the EFC}

Within this social field, the relationship between the AFL and EFC is based on the law of contract and a system of trust, underpinned by a network of economic and personal relationships, incorporating additional ingredients of cultural and social norms. The AFL possesses high levels of symbolic capital, enabling it to assert dominance within this social field. The AFL utilises a range of regulatory tools to control and influence the behaviour of the EFC, including licensing, salary caps, codes of conduct and significantly, control over players through the tripartite contractual arrangements (Harcourt et al., 2014). The benefits bestowed upon the EFC in this relationship enable the EFC to participate within the national competition and receive financial and other support from the AFL.

\subsection{The Legitimate Regulator}

The legal framework provided by the ASADA Act and the NAD Scheme supported the expectation that ASADA would be the ultimate and dominant regulator in managing the EFC investigation. It had the mandate as the driving force for "pure performance in sport" (ASADA, 2006a) backed by the Australian Federal Government. However, when put to the test, gaps were exposed in the legislative regime, resulting in the subject matter for determination in the EFC Court Proceedings and reflected in the judgment that ASADA was expected to cooperate with the AFL. In reality, and as demonstrated from the materials analysed, this regulatory function of implementing the anti-doping regime necessarily relied upon actors external to ASADA and diluted the effect of ASADA's legitimate authority in the social field. Furthermore, ASADA 
became aware of its limited investigative capabilities and as a result, applied for changes in the ASADA Act, which came into effect in August 2013. Senator Humphries (Australian Federal Government, 2014a) acknowledged that:

Recent developments have raised serious questions about what is going on inside our major sporting codes. Ultimately, we do accept the argument that ASADA needs further powers to expand its investigations into doping, but those powers need to be limited and they need to be fully compatible with fundamental legal and human rights that we value so highly in this country. Interestingly, ASADA's new CEO, Ben McDevitt acknowledged ASADA's limitations and lack of capital in handling the EFC investigation (ABC Grandstand, 2014). He commented that, "the reality is that I don't think ASADA was ready for an investigation of this magnitude" (McDevitt, 2014).

The 2013 ASADA amendments did not include increased financial resources to ensure ASADA the capacity to effectively exert its new investigative power. Nor did the ASADA powers extend to compelling answers at interviews (Andruska, 2014). Collaborating with the AFL provided a means to gain resources and access to the clubs implicated in the ACC report. The EFC, through its tripartite agreement with the AFL, had no option but to comply with the investigation once the AFL was involved. The Federal Court proceedings initiated by the EFC targeted the unlawful investigation undertaken by ASADA, but did not seek to extend its scope to challenge the AFL's involvement in the investigation. However, through evidence adduced in the court proceedings, and specifically, the evidence of the then CEO, Aurora Andruska, there were a number of significant revelations that demonstrated that the AFL was motivated to protect its symbolic capital and, specifically, commercial factors such as its brand, the effect on grand final ticket sales and the need to have the matter resolved before the 
2013 finals. For example, in terms of the symbolic capital of the AFL, Andruska (2014) stated in her affidavit that,

In this meeting, Mr McLaughlan said that the AFL was concerned because a survey they had conducted suggested that 'for the first time faith in the game has been challenged'. Mr McLauchlan also said he was concerned about the 'integrity of the 2013 season' and for the 'brand and competition'. He discussed the timing of the conclusion of the investigation and the timing of the 2013 final series (paragraph 36).

An example of the commercial motivations and interests of the AFL can be found in the diary note dated 4 June 2013 and annexed to the Affidavit of Aurora Andruska (Andruska, 2014) as annexure AA-11 referring to the ' 1 million tickets' to be sold and the impact of the ASADA investigation on the interests of the AFL.

As the governing body and regulator of Australian rules football, the AFL was able to leverage off the results of the ASADA investigation and act to protect the integrity of its sport by imposing sanctions against the EFC and a number of support personnel and officials. The AFL's effectiveness as a regulator was supported by those in the social field, despite its lack of legislative legal authority. What has emerged from the findings is that the AFL's access to resources, including the internal integrity unit and its contractual control over players, further cemented its position of power, influence and domination within the social field (Everett, 2002). The AFL was perceived by other field occupants as the dominant actor appropriately wielding power and influence to protect its vested interests. In terms of dominance, one conclusion can be drawn that the AFL was in reality the actor with greater levels of symbolic capital to underwrite its actions. Unfortunately, ASADA has lost social and symbolic capital and consequently, much of its legitimacy, as result of 'unfavourable' media following 
statements from the EFC undermining the investigation conducted by ASADA (Warner, 2014).

The concern raised in this paper is that perceived authority, which is based upon high amounts of organisational capital, does not equate to actual legal (and therefore, legitimate) authority. The central plank of the EFC Court Proceedings was to question the legitimacy of the joint investigation by finding that ASADA acted beyond its powers, and undermined the objective of the anti-doping regime. The mere fact that this action was brought by the EFC demonstrates that there was confusion as to the legitimacy and authority of ASADA. The Federal Court judgment has reinforced ASADA's position, but did not comment on the lack of legitimate legal authority of the AFL. Taxpayer resources were expended by ASADA in defending allegations questioning its legitimacy. The EFC did not appeal the Federal Court finding that ASADA was acting within its power and authority. However, James Hird appealed to the Full Court of the Federal Court but lost the appeal in Hird v Chief Executive Officer of the Australian Ant-Doping Authority [2015] FCAFC 7 ASADA was represented at the appeal, with the expenditure of more taxpayer resources allocated towards responding to the appeal.

In defining legitimacy, Suchman (1995) intimated that organisational legitimacy is "a generalised perception," and is, "appropriate within some socially constructed system of norms, values, beliefs and definitions" (p. 574). Thus, habitus within a social field is determined by dominant organisations within that field; hence, perceptions of legitimacy are the product of these dominant organisations and their determination of habitus (Ihlen, 2007). The findings of this paper suggest actors within a social field perceive dominant actors as the legitimate regulators of behaviour in that space, 
regardless of the legal authority they may or may not possess. In the case of the EFC, the AFL emerged as the dominant regulator in the social field being investigated.

\section{Conclusion}

As highlighted in the EFC case, perceptions of legitimate authority cause concern when organisations operate outside their lawful frameworks, thus leaving loopholes for legal challenges. After a review of the EFC Court Proceedings, it was evident that, in carrying out their regulatory functions and assisting ASADA to enforce the objectives of the ASADA Act and NAD Scheme, ASADA and the AFL exchanged information and collaborated in the investigation of the EFC. Access to the AFL's symbolic capital, resources and forensic capabilities was a critical component to enable ASADA to complete the investigation and to issue the show cause notices to the EFC players.

In the application of Bourdeau's social theory, the AFL, despite its lack of legislative authority, acted with ASADA as a legitimate regulator and utilised its extensive symbolic capital to exert authority in this social field. This research employed Bourdieu's conceptual framework to highlight the importance of organisational capital within a social field. In so doing, the study expands the notion that symbolic capital is sometimes perceived as a source of legitimate authority and regulation within social fields, and points to some of the deleterious consequences of this "misrecognition" of legitimacy

In the case analysed, the EFC Court Proceedings question the collaboration of the AFL and ASADA in regulating anti-doping and have exposed a loophole in the regulatory framework of the anti-doping regime. A retrospective analysis of the EFC investigation demonstrates that ASADA's inadequate legislative framework meant that it depended upon other actors with greater symbolic power - in this case, the AFL. As a 
result of ASADA's dependency on the AFL, the symbolic capital of the AFL was increased, thus further enhancing its dominant position within the social field. The investigation into the EFC highlights the urgent need to fill the regulatory gap identified in this paper to ensure that a clear legislative framework is established as the platform upon which ASADA bases its operations in the future pursuit of pure performance in sport.

\section{Afterword}

The AFL's Anti-Doping Tribunal handed down a decision on 31 March 2015 that it was not comfortably satisfied that any player violated the AFL's Anti-Doping Code. Following this decision, the World Anti-Doping Agency (WADA) issued notification that it was exercising its independent right and appealing the decision of the AFL Tribunal to the Court of Arbitration (CAS) of Sport. A panel of CAS arbitrators has been appointed and the matter has been set down for hearing on 16 November 2015 in Sydney (Court of Arbitration, 2015).

The ramifications of this decision to appeal means that the CAS will examine the evidence and opens the way for the possibility of a different outcome and finding of anti-doping rule violations and the imposition of sanctions. It is beyond the scope of this paper to postulate about exactly what that decision will be, but the fact that WADA has exercised its right to appeal suggests a question over the efficacy of the existing regulatory oversight of the anti-doping regime in Australia. 


\section{References}

ABC Grandstand Sport 'Chief executive Ben McDevitt admits ASADA not equipped to deal with Essendon, Cronulla Investigations'. August 24, 2014 retrieved 24 August 2014, from http://www.abc.net.au/news/2014-08-24/asada-out-of-depthin-supplement-investigation3a-mcdevitt/5692600

AFL. (2013a). Annual Report 2013. http://www.afl.com.au/afl-hq/annual-reports

AFL. (2013b). List of sanctions against Essendon and its officials. Retrieved 23 July, 2014, from http://www.afl.com.au/news/2013-08-27/list-of-chargesagainst-essendon-and-its-officials

AFL. (2013c). National Anti-Doping Code. Retreived 12 August, 2014 from http://www.afl.com.au/policies

AFL. (2014). Corporate Governance. Retrieved 23 August, 2014, from http://www.afl.com.au/staticfile/AFL Tenant/AFL/Files/AFL Corporate Governance.pdf

Andrews, K. (2005). The Australian Sports Anti-Doping Authority Bill 2005.

Retrieved 23 July, 2014, from http://parlinfo.aph.gov.au/parlInfo/search/display/display.w3p;db=CHAM BER;id=chamber\%2Fhansardr\%2F2005-1207\%2F0024; query=Id\%3A\%22chamber\%2Fhansardr\%2F2005-12$\underline{07 \% 2 \mathrm{~F} 0000 \% 22}$

Andruska, A. K. (2014). Affidavit. Retrieved 8 August, 2014, from http://www.fedcourt.gov.au/case-management-services/access-to-filesand-transcripts/online-files/essendon-v-asada. 
ASADA. (2006a). Australian Sports Anti-Doping Authority Act. Retrieved 7 August, 2014, from http://www.comlaw.gov.au/Details/C2013C00512

ASADA. (2006b). Australian Sports Anti-Doping Authority Regulations. Retrieved 8 August 2014, from http://www.comlaw.gov.au/Details/F2013C00745

Augestad, P., Bergsgard, N. A., \& Hansen, A. (2006). The institutionalisation of an elite sport organisation in Norway: The case of Olympiatoppen. Sociology of Sport Journal, 13, 293-313.

Australian Bureau of Statistics (2015). Feature Article 1. Football: Four Games, One Name. Retrieved March 22, 2015 from http://www.abs.gov.au/AUSSTATS/abs@.nsf/Lookup/4156.0.55.001Feature+A rticle1May\%202009

Australian Crime Commission. (2013). Organised crime and drugs in sport. Canberra. Australian Federal Government. (2014a). Essendon v ASADA. Retrieved 15 August, 2014, from http://www.fedcourt.gov.au/case-management-services/access$\underline{\text { to-files-and-transcripts/online-files/essendon-v-asada. }}$

Australian Federal Government. (2014b). Judgements. Retrieved 23 September, 2014, from http://www.judgments.fedcourt.gov.au/judgments/Judgments/fca/single/ $\underline{2014 / 2014 \text { fca1019 }}$

Australian Government (2015) Football in Australia. Retrieved 15 March, 2015, from http://www.australia.gov.au/about-australia/australian-story/football-in-australia Australian Sports Commission. (2009b). Eligibility Criteria for the Recognition of NSOs by the Australian Sports Commission 2009-2013

Black, J. (2002). Critical reflections on regulation. Australian Journal of Legal Philosophy, 1 . 
Bourdieu, P. (1984). In Distinction: A social critque of the judgement of taste. London: Routledge.

Bourdieu, P. (1985). The social space and the genesis of groups. Theory and Society, 14(6), 723-744.

Bourdieu, P. (1990). The logic of practice. Campbridge: Polity.

Bourdieu, P., \& Wacquant, L. J. D. (Eds.). (1992). An invitation to reflexive sociology. Chicago: University of Chicago Press.

Bourdieu, P. (1996). The Rules of Art, Cambridge: Polity Press

Corlett, J. A. (2013). Doping: Just Do It? Sport, Ethics and Philosophy, 7(4), 430-449. doi: $10.1080 / 17511321.2013 .851731$

Cousens, L., \& Slack, T. (2005). Field-level change: The case of North American major league professional sport. Journal of Sport Management, 19, 13-42.

Court of Arbitration (2014) Latest news and Media Releases. Retrieved on 22 October 2015 from http://www.tas-cas.org/en/index.html

Crabtree, B., \& Miller, W. (1992). A template approach to text analysis: developing and using codebooks. In B. Crabtree \& W. Miller (Eds.), Doing Qualitative Research. Newbury Park: Sage.

Dickinson, C., \& Quirk, F. (2010). Understanding doping decisions in sport. Journal of Science and Medicine in Sport, 12, Supplement 2(0), e219-e220. doi: http://dx.doi.org/10.1016/j.jsams.2009.10.459

Edwards, A., \& Skinner, J. (2009). Qualitative research in sport management. Oxford: Butterworth-Heinemann.

Eichner, E. R. (2008). Doping in Sport: Global and Ethical Issues. Journal of Sports Sciences, 26(6), 671-672. doi: 10.1080/02640410701731377 
Emirbayer, M., \& Johnson, V. (2008). Bourdieu and organisational analysis. Theory and Society, 37, 1-44.

Essendon Football Club. (2013). 2013 Annual Report. Essendon.

Evans, D. (2013). Essendon Statement. Retrieved 25 July, 2014, from https://http://www.theage.com.au/afl/afl-news/essendon-statement20130205-2dwak.html

Everett, J. (2002). Organisational research and the praxeology of Pierre Bourdieu Organisational Research Methods, 5(1), 56-80.

Ferkins, L., Shilbury, D., \& McDonald, G. (2009). Board involvement in strategy: Advancing the governance of sport organisations. Journal of Sport Management, $23,245-277$.

Freiberg, A. (2010). The tools of regulation. Australia: The Federation Press.

Fridman, S., \& Buti, A. (2001). Sport and the law. Scribblers Publishing.

Gordon, M. (2013). Blackest day in Australian sport. Sydeny Morning Herald. Retrieved 8 February, from http://www.smh.com.au/sport/blackest-day-inaustralian-sport-20130207-2e1mb.html

Greenhow, A., \& East, J. (2014). Custodians of the game: Ethical considerations for football governing bodies in regulating concussion management. Neuroethics. doi: $10.1007 / \mathrm{s} 12152-014-9216-1$

Harcourt, P., Marclay, F., \& Clothier, B. (2014). A forensic perspective of the AFL investigation into peptides: An anto-doping investigation case study. British Journal of Sports Medicine.

Houlihan, B. (2013). Commercial, political, social and cultural factors impacting on the management of high performance sport. In P. Sotiriadou \& V. De Bosscher (Eds.), Managing High Performance Sport. Milton Park: Routledge. 
Houlihan, B. (2014). Achieving compliance in international anti-doping policy: An analysis of the 2009 World Anti-Doping Code. Sport Management Review, 17(3), 265-276. doi: http://dx.doi.org/10.1016/j.smr.2013.10.002

Ihlen, O. (2007). Building on Bourdieu: A sociological grasp of public relations. Public Relations Review, 33, 269-274.

Kitchin, P., \& Howe, P. (2013). How can social theory of Pierre Bourieu assist sport managment research? Sport Management Reveiw, 16, 123-134.

Krippendorff, K. (2004). Content analysis: An introduction to methodology (2nd Edition ed.). Thousand Oaks, CA: SAGE.

Linnell, G. (1995). Football Ltd: The inside story of the AFL. Sydney: Ironbark. Lundy, K. (2006). The Australian Sports Anti-Doping Authority Bill 2005. Retrieved 23 July, 2014, from http://parlinfo.aph.gov.au/parlInfo/search/display/display.w3p;adv=yes;0 $\underline{\text { rderBy=customrank;page }=0 ; \text { query=Senator Kate Lundy AUSTRALIAN }}$ $\underline{\text { SPORTS ANTI-DOPING AUTHORITY BILL 2005;rec=0;resCount=Default }}$

McDermott, M., Henne, K., \& Connor, J. (2013). Legitimating the fight? Questions about cross-cultural perspectives on anti-doping strategies in the Pacific. Paper presented at the Second Crime and Sport Research Conference, Gold Coast.

McDevitt, B. (2014). Extended interview with ASADA boss Ben McDevitt. In G. Whateley (Ed.), Offsiders: ABC.

Miles, M. B., \& Huberman, A. M. (1994) Qualitative data analysis ( $2^{\text {nd }}$ ed.). London: Sage.

Moston, S., Engelberg, E.T., \& Skinner, J. (2015). Perceived incidence of drug use in Australian sport: a survey of athletes and coaches. Sport in Society, 18(1), 91105. 
Neuman, W. L. (2003). Social research methods (5th ed.). Boston: Pearson Education, Inc.

Newton, D. E. (2013). Steroids and doping in sports: A reference handbook: ABCCLIO.

O'Brien, D., \& Slack, T. (2003). An anaysis of change in an organisational field: The professionalisation of English Rugby Union. Journal of Sport Management, 17, 417-448.

Parker, C. (2002). The Open Corporation: Effective self-regulation and democracy. Cambridge: Cambridge University Press.

Pellandini-Simanyi, L. (2014) Bourdieu, ethics and symbolic power. The Sociological Review, 62, 651-674.

Shilbury, D., \& Ferkins, L. (2011). Professionalisation, sport governance and strategic capability. Managing Leisure, 16(2), 108-127.

Sideri, K. (2004). Questionaing the neutrality of preocedural law: Internet regulation in Europe through the lenses of Bourdieu's notion of capital. European Law Journal, 10(1), 61-86.

Slack, T., \& Hinings, B. (1992). Understanding change in national sport organisations: An intergration of theoretical perspectives. Journal of Sport Management(6), 114-132.

Stewart, B., Adair, D., \& Smith, A. (2011). Drivers of illicit drug use regulation in Australian sport. Sport Management Reveiw, 14, 237-245.

Stewart, B., \& Smith, A. (2010). The role of ideology in shaping drug use regulation in Australian sport. International Review for the Sociology of Sport, 45(2), 187198. 
Suchman, M. C. (1995). Managing legitimacy: Strategic and institutional approaches. Academy of Managment Review, 20(3), 571-610.

Swartz, D. (1997). Culture and Power: The sociology of Pierre Bourdieu. Chicago: The University Press of Chicago Press.

Thorpe, D., Buti, A., Davies, C., Fridman, S., \& Jonson, P. (2013). Sports Law. Australia: Oxford University Press.

WADA. (2014). World Anti Doping Code. Retrieved 5 August, 2014, from https://elb.wada-ama.org/en/what-we-do/the-code

Warner, M. (2014). Essendon blasts former ASADA chief Aurora Andruska following Federal Court trial. Retrieved 27 August 2014, from http://www.heraldsun.com.au/sport/afl/essendon-blasts-former-asadachief-aurora-andruska-following-federal-court-trial/story-fni5f6kv$\underline{1227039214758 ? \mathrm{nk}=3 \mathrm{df} 118 \mathrm{dfaf} 978 \mathrm{da} 743583 \mathrm{baf6066f8e6}}$

Washington, M., \& Patterson, K. (2011). Hostile takeover or joint venture: Connections between institutional theory and sport management research. Sport Management Reveiw, 14, 1-12.

Washington, M., \& Ventresca, M. J. (2008). Institutional contradictions and struggles in the formation of US Collegiate Basketball, 1880-1938. Journal of Sport Management, 22, 30-49.

Westerman, P. (2010) Who is regulating the self? Self regulation as outsourcerd rulemaking. Legisprudence, IV(3), 225-241.

Yin, R.K. (2003) Case study research: design and methods. California: SAGE Publications Ltd 